\title{
The Road to Enablement for a Liquid-Fuel Reactor Fuelled by Thorium
}

\author{
John Durham
}

\begin{abstract}
There is growing recognition that thorium-fuelled Molten Salt Reactors (MSRs) will be one of the key clean energy technologies of the 21st Century. However, thus far few people have addressed the question of how to expedite MSRs' development and deployment. We must avoid a situation where MSRs are "always ten years away". This presentation will suggest several solutions to this quandary. The first part will address the economic and political hurdles that stand in MSRs' way: in the context of historically low levels of fission R\&D, how can we leverage private investment in MSRs, and engender public support for MSR R\&D?
\end{abstract}

The second part of the presentation will address the issue of global scientific cooperation: what tools do MSR researchers need to accelerate their research, and how can we, as MSR supporters, lead the development of these tools? For example, should we aim for a global database of MSR safety codes and models? Should scientists call on the OECD Nuclear Energy Agency and IAEA to fund a facility dedicated to MSRs research?

The third part of the presentation will argue that MSR designers must pay close attention to regulatory requirements from the outset of their research. If a design is too complex, then the chance of regulatory approval, and therefore investment, is slim. In order to satisfy both regulators and potential investors, future MSRs must not look to directly imitate the Oak Ridge design, but rather to simplify the reactor system. For example, is it possible to "design out" the more troublesome components of MSRs such as pumps and valves? Could we design an MSR that uses only previously certified materials?

In light of the points above, the final part will posit a draft road-map of MSR development, leading from simple once-through burner to fully fledged fast-spectrum reactor. We will conclude by arguing that the road to MSR enablement requires MSR designers to "Economise, Collaborate, and Simplify".

No contribution submitted by the author.

J. Durham $(\bowtie)$

Weinberg Foundation, Somerset House, Strand, London, WC2R

1LA, UK 